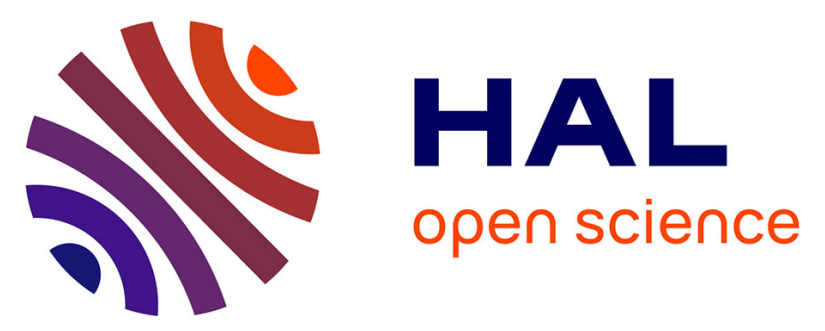

\title{
A polymorphism in the glutamate metabotropic receptor 7 is associated with cognitive deficits in the early phases of psychosis
}

Boris Chaumette, Sarojini M Sengupta, Martin Lepage, Ashok Malla, Srividya N Iyer, Oussama Kebir, Patrick Dion, Guy Rouleau, Marie-Odile Krebs, Jai L Shah, et al.

\section{To cite this version:}

Boris Chaumette, Sarojini M Sengupta, Martin Lepage, Ashok Malla, Srividya N Iyer, et al.. A polymorphism in the glutamate metabotropic receptor 7 is associated with cognitive deficits in the early phases of psychosis. Schizophrenia Research, 2020, Online ahead of print. 10.1016/j.schres.2020.06.019 . inserm-02892228

\section{HAL Id: inserm-02892228 https://www.hal.inserm.fr/inserm-02892228}

Submitted on 7 Jul 2020

HAL is a multi-disciplinary open access archive for the deposit and dissemination of scientific research documents, whether they are published or not. The documents may come from teaching and research institutions in France or abroad, or from public or private research centers.
L'archive ouverte pluridisciplinaire HAL, est destinée au dépôt et à la diffusion de documents scientifiques de niveau recherche, publiés ou non, émanant des établissements d'enseignement et de recherche français ou étrangers, des laboratoires publics ou privés. 


\title{
A polymorphism in the Glutamate Metabotropic Receptor 7 is associated with cognitive deficits in the early phases of psychosis
}

\author{
Boris Chaumette ${ }^{1,2,3,4}$, Sarojini M. Sengupta ${ }^{4,5}$, Martin Lepage ${ }^{4,5}$, Ashok Malla ${ }^{4,5}$, \\ Srividya N. Iyer ${ }^{4,5}$, Oussama Kebir ${ }^{2,3}$, ICAAR study group ${ }^{a}$, Patrick A. Dion ${ }^{1}$, Guy A. Rouleau ${ }^{1}$, \\ Marie-Odile Krebs ${ }^{2,3}$, Jai L. Shah ${ }^{4,5 *}$, Ridha Joober ${ }^{4,5 *}$
}

1. Montreal Neurological Institute and Hospital, Department of Neurology and Neurosurgery, McGill University, Montreal, Quebec, Canada

2. Université de Paris, Institute of Psychiatry and Neuroscience of Paris (IPNP), INSERM U1266, CNRS, GDR3557-Institut de Psychiatrie, Paris, France

3. GHU Paris Psychiatrie et Neurosciences, Paris, France

4. Department of Psychiatry, McGill University, Montreal, Quebec, Canada

5. Douglas Mental Health University Institute, Montreal, Quebec, Canada

a. group authorship : ICAAR study group includes Isabelle Amado, Julie Bourgin, Claire Daban Huard, Célia Jantac Mam-Lam-Fook, Marion Plaze, Fabrice Rivollier

* these authors contribute equally to this work

Corresponding author: Dr Boris Chaumette boris.chaumette@mcgill.ca Irving Ludmer Building - 1033, Pine av. Room: 327 Montréal, Québec, H3A 1A1 - Canada

Contributors of the ICAAR study group: Isabelle Amado, Julie Bourgin, Claire Daban Huard, Célia Jantac Mam-Lam-Fook, Marion Plaze, Fabrice Rivollier 


\begin{abstract}
Schizophrenia is an illness characterized by positive symptoms, negative symptoms, and cognitive impairments. Cognitive impairments occur before the onset of psychosis and could reflect glutamatergic dysregulation. Thus, identifying associations between genetic variations in genes coding for glutamatergic receptors and cognitive impairment in schizophrenia may help in understanding the basis of these deficits and in identifying potential drug targets. In a discovery cohort of 144 first-episode of psychosis patients (FEP), we genotyped 58 candidate Single Nucleotide Polymorphisms (SNPs) located in NMDA and metabotropic glutamatergic receptors. These SNPs were selected according to the results from the Psychiatric Genomic Consortium and were tested for association with intellectual quotient (IQ) as assessed with the Wechsler Intelligence Scale. For replication, we used the ICAAR cohort including 121 ultra-high-risk patients (UHR) with the same cognitive assessment. A polymorphism located in GRM7, rs1396409, was significantly associated with performance IQ in the discovery cohort of FEP. This association was replicated in the UHR cohort. This polymorphism is also associated with total IQ and verbal IQ in the merged dataset, with a predominant effect on the arithmetic subtest. The rs 1396409 polymorphism is significantly associated with cognitive impairment during the onset of psychosis. This genetic association highlights the possible impact of glutamatergic genes in cognitive deficits in the early phases of psychosis and enforce the interest for new therapeutic interventions targeting the glutamatergic pathway.
\end{abstract}

Keywords: premorbid - IQ - schizophrenia - prodromal - psychosis - genetics

Word in text: 3,322

Tables: 3

Figure: 0

Supplementary Tables: 2

Supplementary Figure: 1 


\section{Introduction}

Schizophrenia is a neurodevelopmental disorder typically beginning in adolescence or early adulthood. The main manifestations of schizophrenia and related psychoses are positive symptoms (e.g. hallucination, delusions and disorganized thinking), negative symptoms (e.g. flat affect, lack of socialization), disorganization and cognitive impairments (Owen et al., 2016). Antipsychotics, the first line treatment for schizophrenia, are effective mainly for positive symptoms and their action on the other symptoms is limited (Kahn et al., 2015). Thus, identifying therapeutic targets for negative symptoms and cognitive impairments, both believed to be important for functional recovery, is an important line of investigation (Green and Harvey, 2014).

Variation in cognitive functioning and liability to schizophrenia could share genetic factors as suggested by twin (Toulopoulou et al., 2007), genome-wide association (Smeland et al., 2017) and polygenic risk score studies (Lencz et al., 2014). Cognitive deficits may predate the onset of psychosis (Bora and Murray, 2014): neuropsychological studies have demonstrated that unaffected relatives of patients with schizophrenia (individuals at familial high-risk for schizophrenia, FHR) perform poorly compared to healthy controls in all cognitive domains (Agnew-Blais and Seidman, 2013), and cognitive impairments are present in subjects with subthreshold psychotic symptoms who are at ultra high-risk (UHR) for psychosis (Fusar-Poli et al., 2012; Mam-Lam-Fook et al., 2017). Patients with a first episode of psychosis (FEP) present global cognitive impairment, particularly in verbal memory and executive function, compared to healthy volunteers (Aas et al., 2014). These early deficits impact general IQ and contribute to deficits in social and occupational functioning (Grau et al., 2016).

Developing new phase-specific interventions targeting cognitive deficits (Millan et al., 2016) may be effective in preventing the onset of cognitive and functional deficits (Nuechterlein et al., 2014). Among the currently-available drugs, modulators of glutamatergic receptors are promising. Since 
the pioneering trial about oral glycine on negative symptoms in schizophrenia (Leiderman et al., 1996), several studies have tested modulators of the metabotropic glutamate receptors (Matosin and Newell, 2013) and modulators of the N-methyl-D-aspartate receptor (NMDAR) including Dserine or glycine in add-on in chronic schizophrenia (Kantrowitz et al., 2010). Despite mixed findings of their attenuation of cognitive deficits in later stages (Iwata et al., 2015), these treatments may have efficacy when used earlier, during UHR stages (Kantrowitz et al., 2015). Modulation of $\mathrm{N}$-methyl-D-aspartate receptor has also been reported to improve psychotic symptoms in patients carrying a rare copy-number variant encompassing glutamatergic genes (Bodkin et al., 2019) suggesting efficacy in patients with specific genetic factors. Indeed, rare variants in NMDAR have been associated with schizophrenia (Tarabeux et al., 2011). Common variants associated with schizophrenia pointed towards genes related to synaptic function and expressed in pyramidal glutamatergic neurons (Skene et al., 2018). In addition, N-methyl-Daspartate-type glutamate receptor (NMDAR) antagonists, such as ketamine, induce cognitive deficits and symptoms closely resembling those of schizophrenia (Anticevic et al., 2012; Vinckier et al., 2016). Consequently, it has been postulated that dysregulation in glutamate neurotransmission may play a significant role in cognitive impairments observed in schizophrenia (Thomas et al., 2017) and may also play a role in the emergence of psychotic symptoms. A metaanalysis of brain spectroscopy studies in patients with UHR revealed that medial frontal glutamate plus glutamine levels are increased compared to healthy controls (Merritt et al., 2016). Recent reports suggest that glutamate level could be higher in FEP compared to controls in the cingular cortex (Chiu et al., 2017; Kim et al., 2017) and striatum (Plitman et al., 2016).

Thus, studying the link between glutamatergic neurotransmission and cognitive impairment during the early phases of psychosis may improve our knowledge about the mechanisms underlying cognitive impairments in schizophrenia and provide clues about new therapeutic 
targets. Whereas research on the genetics of neurocognitive domains in schizophrenia has grown rapidly over the last decade, the glutamatergic system remains insufficiently explored (Zai et al., 2017).

The objective of the present study was to explore associations between polymorphisms in glutamatergic receptors and cognition during the onset of psychosis. We first tested the association between cognition and candidate polymorphisms in sixteen glutamatergic receptors (Supplementary Table 1) in a discovery cohort of well-phenotyped FEP. Subsequently, we attempted to replicate any significant association in a cohort of UHR subjects.

\section{Methods}

\section{Samples}

In the FEP cohort, 260 Caucasian individuals were recruited from among patients treated at the Prevention and Early Intervention Program for Psychoses in Montreal (PEPP-Montréal) between 2003-2013 (lyer et al., 2015). Inclusion criteria were an age between 14 and 35 years, less than 30 cumulative days of antipsychotic treatment, and a FEP diagnosis according to the Structured Clinical Interview for DSM-IV-TR (Diagnostic and Statistical Manuel for Mental Disorders, fourth edition, text revised). All diagnoses were confirmed at a consensus meeting attended by a senior research psychiatrist (AM or RJ). All patients gave their written informed consent. The study was approved by the Ethics Review Board at the Douglas Mental Health University Institute and at McGill University.

For the UHR cohort, 173 Caucasian UHR individuals were recruited in the French ICAAR cohort (PHRC AOM-07-118, promoted by Hôpital Sainte-Anne) among the patients (16 to 30 years old) consecutively referred to the Adolescent and Young Adult Assessment Centre (Service Hospitalo- 
Universitaire, Hôpital Sainte-Anne, Paris, France) between 2009 and 2014 (Oppetit et al., 2016). The cohort was approved by the institutional ethics committee "Comité de protection des personnes, Ile-de-France III, Paris, France" and written informed consent was obtained from all participants. UHR status was determined based on the CAARMS criteria in its French-translated version (Krebs et al., 2014). Exclusion criteria included current antipsychotic treatment at a chlorpromazine equivalent dose higher than $100 \mathrm{mg}$ for more than twelve weeks, manifest symptoms of established psychiatric diagnoses including psychosis, psychoactive substance dependence or abuse (fulfilling DSM-IV criteria), serious or non-stabilized somatic and neurological disorders, head injury, IQ below 70, and non-French-native speaking (because of the cognitive assessment)

The criteria about dose and duration of the antipsychotic treatments were chosen to select minimally treated patients and to avoid a possible deleterious effect of antipsychotics on cognition. The demographic and baseline clinical characteristics of PEPP and ICAAR cohorts are described in Table 1. All procedures at both sites complied with the ethical standards of the relevant national and institutional committees on human experimentation and with the Helsinki Declaration.

\section{Cognitive assessment}

In the FEP cohort, full- (FIQ), verbal- (VIQ), and performance (PIQ) were evaluated in 148 individuals using the Wechsler Adult Intelligence Scale (WAIS-III) during a face-to-face interview conducted by trained staff under the supervision of licensed neuropsychologists.

In the UHR cohort, the 9-subtest version of the WAIS-III was administered in approximately ninety minutes in 153 UHR individuals by trained psychologists. This version includes: Vocabulary, 
Similarities, Information (constituting the Verbal Comprehension Index, $\mathrm{VCl}$ ), Arithmetic, Digit Span, Picture Completion, Block Design, Matrix Reasoning (constituting the Perceptive Organization Index, POI) and Digit Symbol-Coding subscale (part of Processing Speed Index, PSI). The scores were age-scaled and normalised as recommended in the WAIS-III manual and Wechsler's instructions as previously reported (Magaud et al., 2014).

\section{SNP selection and genetic assessment}

In the FEP cohort, DNA were sampled from whole-blood for each Caucasian participant and extracted following classical protocols. Fifty-eight SNPs located either in NMDA- or metabotropic glutamate receptors (Supplementary table 1) were genotyped using Sequenom iPlex Gold Technology in the Genome Quebec Innovation Centre. The SNPs were selected based on their association with schizophrenia according to the Psychiatric Genomics Consortium (PGC, data freely available online: http://www.med.unc.edu/pgc) using the following rationale: (1) We first selected 16 SNPs, each in one of the glutamatergic receptors with the lowest $p$-value in the PGC dataset. This selection was performed to select at least one SNP by gene. (2) Second, we selected 42 tag-SNPs in glutamatergic receptor genes. Tag-SNPs are supposed to be representative SNPS in a region of the genome with high linkage disequilibrium that represents a group of SNPs. 979 Tag SNPs were identified in the 16 genes according the HapMap CEU database and using the NIH online software https://snpinfo.niehs.nih.gov/snpinfo/snptag.html. Tag-SNPs were retained if they tag at least 5 SNPs and have a nominal p-value $<0.05$ in association with schizophrenia in the PGC database. Six SNPs failed to be genotyped in the cohort due to low intensity (Supplementary Table 1).

The SNP found to be associated with cognition in the FEP cohort was subjected to a replication in the UHR cohort including 129 individuals. This cohort has been genotyped using the Illumina Infinium PsychArray BeadChip, specifically designed by the PGC for psychiatric disorders, and 
covering half a million SNPs in the whole genome. The significant SNP was directly extracted from the genotyping data. Eight individuals failed to be genotyped in the UHR cohort.

\section{Genetic analyses}

The statistical analyses were conducted in Plink v1.07. The FEP cohort was composed of 148 individuals with both cognitive assessment and genetic data. In this cohort 43 SNPs were retained (Supplementary Table 1) after quality control using the following criteria: (1) greater than $90 \%$ of attempted genotypes were successful, (2) SNPs were in Hardy-Weinberg equilibrium (with a 0.001 threshold), (3) minor allele frequency was greater than 5\% (Supplementary table 1). The UHR cohort included 121 individuals with non-missing genotype and non-missing phenotype. The extracted SNP had a minor allele frequency of 0.42 in the UHR cohort. Three alternate phenotypes were used in the FEP cohort (VIQ; PIQ; FIQ) and five in the UHR cohort (VIQ; PIQ; FIQ; VCl; POI) as well as subscores for each cohort. Quantitative trait associations were performed using the Wald test. For the FEP cohort, the Wald test asymptotic $p$-value was corrected for the number of selected SNPs using the Bonferroni method. The alpha-risk was set to 0.05 after correction. Then, we conducted the same analysis in the merged cohort (265 individuals in total) for the three overlapping phenotypes (VIQ; PIQ; FIQ) using 10,000 permutations. The SNP explored in the merged cohort had a minor allele frequency of 0.41 .

\section{Results}

In the FEP cohort, the association with FIQ, VIQ and PIQ was tested for each of the 43 SNPs, located in one of the following glutamatergic genes: GRIN2A, GRIN2B, GRIN3A, GRM1, GRM3, GRM4, GRM5, GRM7 and GRM8 (Supplementary Table 2). Only one SNP, rs1396409 was significantly associated with performance IQ after multiple-testing correction (non-missing individuals $=144$; uncorrected $p$-value $=9.5 .10^{-4}$; corrected $p$-value $=0.041$ ). This SNP is located in (hg19) chr3:7302907 and encompass the GRM7 gene. It was not associated with VIQ nor with 
total FIQ score. Then, we performed a detailed association between this SNP and each sub-test of the IQ test in the same cohort (Table 2). In the UHR cohort, only the SNP rs1396409 was analyzed. This SNP was significantly associated with PIQ, FIQ and POI, but was not associated with VIQ nor $\mathrm{VCl}$ (non-missing individuals=121) (Table 2).

The two cohorts were merged in a whole dataset ( $n=265$ individuals). The SNP rs1396409 was analyzed and 10,000 permutations were done. This SNP was significantly associated with VIQ, PIQ and FIQ (Table 2). The association was significant for the arithmetic subtest of the WAIS and nearsignificant for the block design and the information subtests. Different genetic models were tested (Table 3): the SNP was more significantly associated with FIQ, VIQ and arithmetic subtest in a T-allele dominant model whereas it was more significantly associated with PIQ in an additive model. The effect is not due to outliers and we report a real shift of the distribution of IQ depending on the genotypes (Supplementary Figure 1).

\section{Discussion}

In the present study testing 43 SNPs in 9 glutamatergic genes, only one SNP, located in GRM7 was associated with cognition in the early phases of psychosis. We found that the $C$ allele of rs 1396409 was significantly associated with lower PIQ in UHR and FEP cohorts with an additive effect for the C allele. Interestingly the association of this SNP with VIQ became significant only in the merged dataset with a recessive effect of the $C$ allele. This difference could be explained because the effect on VIQ is less important than on PIQ: loss of 5 VIQ points compared to 10 PIQ points in the $C$ allele homozygous carriers. This effect may have required a larger sample size to identify. The effect on full IQ is also significant and could be mediated by the significantly worse performance on the arithmetic subtest in $C$-allele homozygous individuals compared to the $T$-allele carriers. 
Association of rs1396409 with two other subtests (information and block design) approached significance in the total data set.

In a previous mega-analysis of the general population (Sniekers et al., 2017), rs1396409 was not found to influence human intelligence $(p=0.429)$. Nevertheless, an exploration of the UK Biobank data showed that this SNP has a close to significance association with "age completed full time education" (http://big.stats.ox.ac.uk/variant/3:7302907-G-A), a factor correlated with IQ (Plomin and Stumm, 2018). This SNP was not reported to be associated with general cognition in schizophrenia (Smeland et al., 2017). This, combined with results from the current analysis, may indicate that this SNP is specifically associated with cognitive deficits during the onset of psychotic illness. This could be because cognitive deficits in later phases of the illness may stem from multiple other sources such as social deprivation and the effect of medication, which can dilute any genetic association. It is also possible that the genetic underpinnings of cognitive deficits in psychosis may be phase-specific and that cognitive deficits in later stages of the illness may stem from different genetic mechanisms compared with those in early stages. However, the lack of association of this SNP with cognition both in the general population and in chronic schizophrenia could also be due to difference in methodology. For example, large studies investigated the $G$ factor instead of full IQ. G factor refers to the general intelligence factor, a psychometric construct deemed to summarize an individual's intelligence based on the person's performance to different cognitive tasks. Whereas $\mathrm{G}$ factor may capture the general cognitive ability, it is much less detailed than the WAIS test we used in both of our datasets. Although the WAIS assessment is timeconsuming, it provided a detailed cognitive measure with a well-validated face-to-face test.

In summary, we propose that this SNP is associated with cognitive impairment during the onset of psychosis. This association may be masked by other factors in chronic states where etiology of cognition deficits could be more heterogeneous (Cohen and Murante, 2017), under the influence 
of long-term medication (Hulkko et al., 2017; Husa et al., 2014) or the "toxic biopsychosocial" impact of the illness progression (Brewer et al., 2006). Investigating the association between genetics variants and cognitive deficits in the early phases of illness may therefore carry the advantage of circumventing several confounding factors that are present in later phases of the illness and could explain why previous genetic associations with cognition in schizophrenia have not identified this SNP.

The effect of rs1396409 on both VIQ and FIQ is large, with an effect-size that should have clinical utility. For example, it has been estimated that every point decrease in IQ significantly increases the risk of schizophrenia by $3.7 \%$, with a similar effect of verbal and nonverbal measures (Khandaker et al., 2011). Here, we reported a shift in the distribution of IQ, as large as 5 points for VIQ and 10 points for PIQ.

Some limitations need to be kept in mind while interpreting the results of this study. First, we could not exclude that the SNP may be indirectly associated with IQ, via other factors like drug use which has been shown to play a role in cognition in early phases of psychosis (Buchy et al., 2015). Second, we restricted our analysis to the glutamatergic receptors, whereas other genes involved in glutamatergic function have shown to influence cognition in schizophrenia, including genes involved in glutamate reuptake, NEUROG1, MAGI2, DTNBP1... (Thomas et al., 2017). For instance, functional polymorphisms of the excitatory amino-acid transporters EAAT1 and EAAT2 (also called SLC1A3 and SLC1A2 respectively) have been associated with cognitive dysfunction in schizophrenia (Spangaro et al., 2014) but also to a differential response to cognitive remediation therapy in this disorder (Spangaro et al., 2018). Exploring the epistatic interactions between genes involved in the glutamatergic pathway, or more broadly in the excitatory/inhibitory balance, would be an interesting future development. However, testing these interactions would have required larger sample size. Our limited sample size allowed us to identify only one SNP 
significantly associated with cognition in the FEP cohort. To improve our statistical power, we merged cohorts recruited in two different centers. Noteworthy, the cognitive assessment was highly comparable as indicated by the standardization of the tests. While merging both UHR and FEP patients may result in a heterogeneous sample, the phenotypes investigated in this study are commonly described in the psychotic field as the early clinical phases of psychosis. A recent study investigated the difference in cognition between FEP and UHR and found no evidence of cognitive decline between these two stages (Carrión et al., 2018). We acknowledge, however, that cognition in UHR may be different between those who later convert to psychosis and those who do not. In our UHR cohort, $37.3 \%$ will develop a psychotic disorder after the follow-up. Thus, the heterogeneity of the merged cohort should have (if anything) diminished the statistical significance of our results.

The rs1396409 is a tag SNP for 7 other SNPs. All of them are located in the second intron of the GRM7 gene in chr3:7239504-7290152 (hg19). Polymorphisms in this gene have previously been associated with schizophrenia (Li et al., 2016, p. 7) and bipolar disorder (Kandaswamy et al., 2014; Wellcome Trust Case Control Consortium, 2007). It is encompassed by Copy Number Variations associated with schizophrenia (Bassett et al., 2017), ADHD (Elia et al., 2011) and ASD (Liu et al., 2015). Rare truncating variants in GRM7 have been reported in neurodevelopmental disorders with intellectual disabilities (Reuter et al., 2017). GRM7 has also been implicated in response to antipsychotic treatment in psychosis (Sacchetti et al., 2017; Stevenson et al., 2016) with three intronic SNPs associated with poor response to treatment. One of them, rs2133450, is located in the same intron than rs1396409. Homozygotes for the at-risk allele in the CATIE study respond worse to risperidone in term of positive symptoms but also in the general subscale of the PANSS which include measurement of the cognitive deficits (Sacchetti et al., 2017). Recently, several 
SNPs located in GRM7 have been associated with response to various antipsychotics, suggesting its interesting role in pharmacogenetics (Liang et al., 2020).

Interestingly, rs1396409 is predicted by SCANdatabase (Zhang et al., 2015) to be significantly associated with expression of the transcription factor CREB2 (with a $\mathrm{p}$-value at $10^{-4}$ in HapMap Caucasian residents from Utah). CREB2, also known as Activating Transcription Factor 2 (ATF2), is a CREB repressor, meaning that it decreases the CAMP response element-binding (CREB) proteins. It has been shown that the role of GRM7 in neurodevelopment is mediated by the CREB pathway (Xia et al., 2015). When signals arrive at glutamate receptors, a proteinic cascade leads to an activation of CREB proteins. In neurons, CREB pathway is involved in the formation of long-term memories and long-term potentiation. Genetic variations in GRM7 could lead to alteration in the CREB pathway and deficits in learning. GRM7 undergo a progressive age-dependent decrease of expression in the human prefrontal cortex (Choi et al., 2009), suggesting that this gene could be involved in developmental deregulation, including those that are predisposing to psychiatric disorders. Any disruption in this gene may predispose individuals to cognitive deficits, which, in interaction with other risk factors, can increase the likelihood of the emergence of psychotic disorders.

\section{Conclusion}

Exploring the impact of polymorphisms in glutamatergic receptors on cognition in FEP, we detected a significant association between rs1396409 and IQ in this population and replicated this finding in a UHR sample. Cognition is a very important domain in psychosis with a major impact in terms of functioning and functional prognosis; glutamatergic drugs have recently been 
proposed to improve cognition. This study could help to provide rationale to address the cognitive deficits in the early phases of psychosis with these new therapeutic drugs. 
Table 1: description of the population including the baseline clinical scores

\begin{tabular}{|c|c|c|}
\hline & FEP cohort & UHR cohort \\
\hline Sample & 148 first-episode of psychosis & 129 ultra-high risk \\
\hline Genotyping & Panel of 58 SNPs & $\begin{array}{l}\text { Extraction from the PsychArray } \\
\text { genotyping data }\end{array}$ \\
\hline Phenotypic presentation & $\begin{array}{l}77.6 \% \text { non affective } \\
22.4 \% \text { affective }\end{array}$ & $\begin{array}{c}\text { 37.4\% will develop a psychotic } \\
\text { disorder }\end{array}$ \\
\hline Sex & $\begin{array}{l}75.2 \% \text { male } \\
24.8 \% \text { female }\end{array}$ & $\begin{array}{l}59.7 \% \text { male } \\
40.3 \% \text { female }\end{array}$ \\
\hline Mean age $( \pm S D)$ & $22.7 \pm 3.7$ & $21.5 \pm 3.5$ \\
\hline Mean SOFAS ( \pm SD) & $42.7 \pm 13.2$ & $47.3 \pm 10.0$ \\
\hline Mean SANS ( \pm SD) & $31.2 \pm 15.4$ & $30.6 \pm 21.0$ \\
\hline Mean SAPS ( \pm SD) & $35.2 \pm 14.8$ & $16.1 \pm 12.9$ \\
\hline Mean PANSS ( \pm SD) & $83.9 \pm 16.8$ & $69.7 \pm 17.6$ \\
\hline Mean VIQ ( \pm SD) & $94.4 \pm 15.3$ & $104.0 \pm 13.9$ \\
\hline Mean PIQ ( \pm SD) & $91.3 \pm 16.8$ & $98.8 \pm 12.9$ \\
\hline Total IQ ( \pm SD) & $92.8 \pm 15.4$ & $102.0 \pm 13.3$ \\
\hline
\end{tabular}

SOFAS=Social and Occupational Functioning Assessment Scale; SANS=Scale for the Assessment of Negative Symptoms; SAPS= Scale for the Assessment of Positive Symptoms; PANSS=Positive And Negative Syndrome Scale; VIQ=verbal intelligence quotient; PIQ=performance intelligence quotient; $I Q=$ intelligence quotient; $S D=S t a n d a r d$ deviation 
Table 2: Association between rs1396409 and cognitive measures.

\begin{tabular}{|c|c|c|c|c|c|c|c|}
\hline & \multirow{2}{*}{\multicolumn{2}{|c|}{$\begin{array}{l}\text { FEP cohort } \\
(\mathrm{n}=144)\end{array}$}} & \multirow{2}{*}{\multicolumn{2}{|c|}{$\begin{array}{l}\text { UHR cohort } \\
\quad(n=121)\end{array}$}} & \multirow{2}{*}{\multicolumn{2}{|c|}{$\begin{array}{l}\text { Merged dataset } \\
\quad(n=265)\end{array}$}} \\
\hline & & & & & & & \\
\hline & & Beta & $\begin{array}{l}\text { Uncorrected } \\
\text { p-value }\end{array}$ & Beta & p-value & Beta & p-value \\
\hline \multicolumn{2}{|c|}{ Verbal IQ } & 2.94 & 0.11 & 3.40 & 0.07 & 3.257 & 0.02 \\
\hline \multicolumn{2}{|c|}{ Performance IQ } & 6.45 & $9.5 .10^{-4}$ & 3.61 & 0.04 & 5.265 & 2.1.10-4 \\
\hline \multicolumn{2}{|c|}{ Full IQ } & 7.97 & $7.10^{-3}$ & 4.13 & 0.02 & 4.558 & 9.6.10-4 \\
\hline \multirow{3}{*}{$\begin{array}{l}\text { Verbal comprehension } \\
\text { index }\end{array}$} & Vocabulary & 6.25 & 0.06 & 0.52 & 0.20 & 1.15 & 0.40 \\
\hline & Similarities & 1.06 & 0.15 & 0.43 & 0.31 & 0.66 & 0.26 \\
\hline & Information & 1.55 & 0.03 & -0.02 & 0.96 & 0.80 & 0.08 \\
\hline \multirow{2}{*}{ Working memory index } & Arithmetic & 1.00 & 0.03 & 0.79 & 0.04 & 0.87 & $8.2 \cdot 10^{-3}$ \\
\hline & Digit Span & 0.1957 & 0.67 & 0.85 & 0.04 & 0.42 & 0.32 \\
\hline \multirow{3}{*}{$\begin{array}{c}\text { Perceptual } \\
\text { Organisation Index }\end{array}$} & Picture completion & 1.12 & 0.02 & 0.52 & 0.14 & 0.75 & 0.10 \\
\hline & Block Design & 1.55 & $2.6 .10^{-4}$ & 0.90 & 0.04 & 3.31 & 0.06 \\
\hline & Matrix reasoning & $N A$ & $N A$ & 0.31 & 0.39 & $N A$ & $N A$ \\
\hline Processing Speed Index & Digit Symbol Coding & 2.25 & 0.23 & 0.66 & 0.10 & 0.82 & 0.76 \\
\hline
\end{tabular}

FEP=first-episode of psychosis; UHR=ultra-high risk; IQ=intelligence quotient 
Table 3: Genetic models for association between rs1396409 and cognitive domains

\begin{tabular}{|c|c|c|c|c|c|c|}
\hline Genotype & $\begin{array}{l}\text { Number of } \\
\text { individuals }\end{array}$ & frequency & $\begin{array}{c}\text { PIQ } \\
\text { (means } \pm \text { SD) }\end{array}$ & $\begin{array}{c}\text { VIQ } \\
\text { (means } \pm \text { SD) }\end{array}$ & $\begin{array}{c}\text { FIQ } \\
\text { (means } \pm \text { SD) }\end{array}$ & $\begin{array}{c}\text { Arithmetic } \\
\text { (means } \pm \text { SD) }\end{array}$ \\
\hline TT & 41 & 0.15 & $99.9 \pm 14.3$ & $100.8 \pm 14.9$ & $100.8 \pm 13.8$ & $11.4 \pm 3.4$ \\
\hline TC & 138 & 0.52 & $95.9 \pm 15.9$ & $100.3 \pm 15.9$ & $98.5 \pm 15.7$ & $11.2 \pm 3.6$ \\
\hline CC & 86 & 0.33 & $89.8 \pm 14.8$ & $95.2 \pm 14.5$ & $92.4 \pm 14.1$ & $9.9 \pm 3.7$ \\
\hline \multicolumn{3}{|c|}{$\mathrm{p}$-value in the recessive model ( $C$ allele) } & $5.10^{-4}$ & 0.01 & $9.0 .10^{-4}$ & $4.4 .10^{-3}$ \\
\hline \multicolumn{3}{|c|}{$\mathrm{p}$-value in the dominant model ( $C$ allele) } & 0.02 & 0.34 & 0.07 & 0.22 \\
\hline \multicolumn{3}{|c|}{$\mathrm{p}$-value in the additive model } & $2.1 .10^{-4}$ & 0.02 & $9.6 .10^{-4}$ & 0.02 \\
\hline
\end{tabular}

$\mathrm{VIQ}=$ verbal intelligence quotient; $\mathrm{PIQ}=$ performance intelligence quotient; $I \mathrm{Q}=$ =intelligence quotient; $\mathrm{SD}=$ standard deviation 
Supplementary figure 1: Distribution of performance IQ, verbal IQ and full IQ in the merged dataset (FEP+UHR), regarding the genotype for the rs1396409
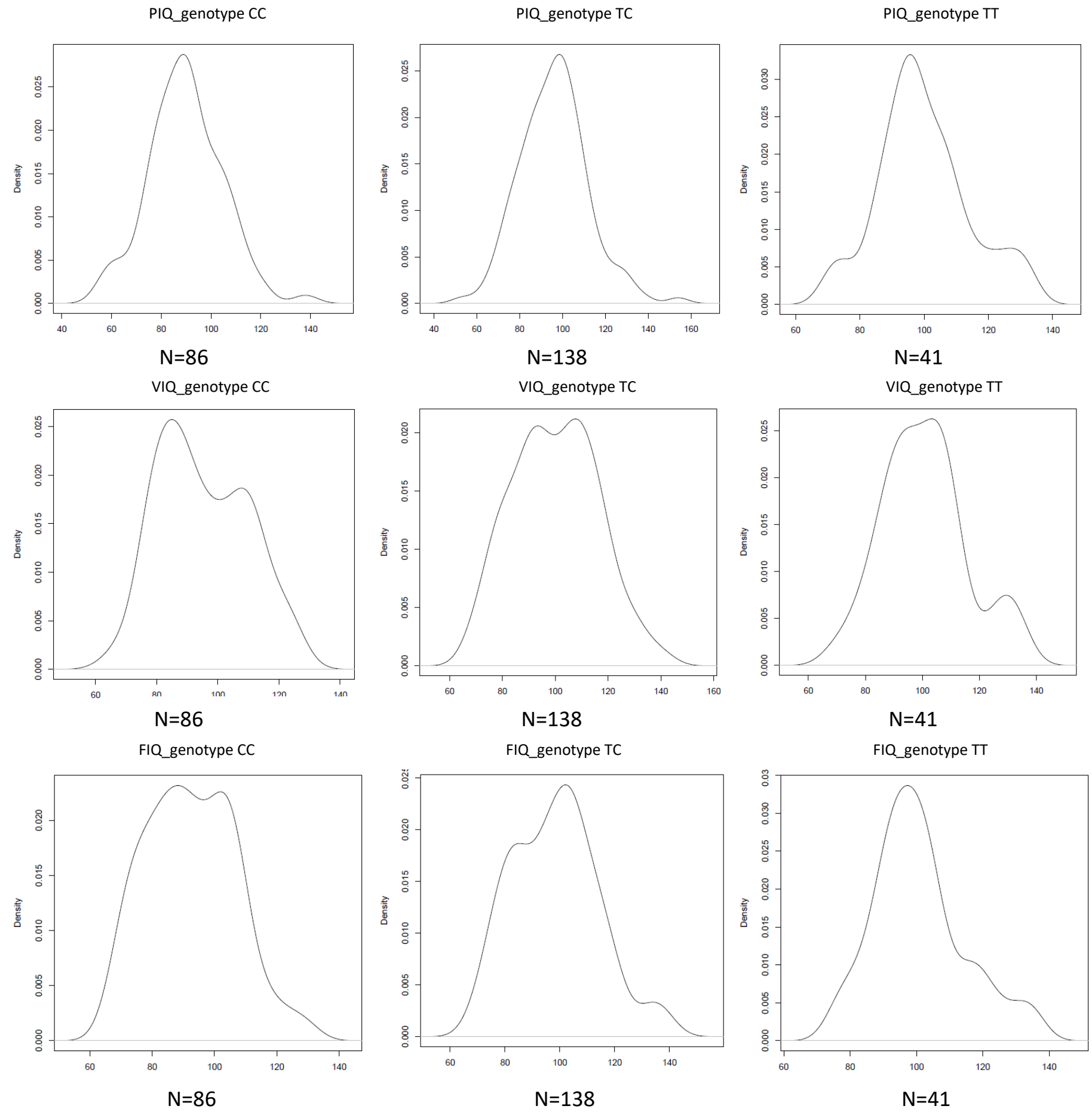
Supplementary Table 1: selection of candidate SNPs and quality control

NMDA ionotropic glutamate receptors (NMDAR) are composed by different sub-units and one associated-protein coding by 8 genes: GRIN1, GRIN2A, GRIN2B, GRIN2C, GRIN2D, GRIN3A, GRIN3B, GRINA. Metabotropic glutamate receptor (mGluR) are encoded by 8 genes: GMR1 to GMR8.

Pass: successfully genotyped and remaining after quality control

Excluded after QC: not surviving after quality control

Failed: failed to be genotyped

\begin{tabular}{|c|c|c|c|c|c|c|c|}
\hline SNP & Chr & Position_hg19 & $\begin{array}{c}\text { nominal p-value } \\
\text { in PGC }\end{array}$ & Gene Name & Criteria of selection & Genotyping & minor allele frequency \\
\hline rs41290007 & chr9 & 140055703 & 0.01076 & GRIN1 & Best SNP in PGC & failed & - \\
\hline rs9922678 & chr16 & 9946319 & $6.72 \mathrm{E}-09$ & GRIN2A & Best SNP in PGC & pass & 0.3442 \\
\hline rs2193146 & chr12 & 13732966 & $1.01 \mathrm{E}-05$ & GRIN2B & Best SNP in PGC & excluded after QC & 0.02778 \\
\hline rs11575878 & chr17 & 72847899 & 0.2459 & GRIN2C & Best SNP in PGC & excluded after QC & 0.05093 \\
\hline rs74192709 & chr19 & 48922695 & 0.01098 & GRIN2D & Best SNP in PGC & excluded after QC & 0.02083 \\
\hline rs1337682 & chr9 & 104491984 & 0.00215 & GRIN3A & Best SNP in PGC & pass & 0.257 \\
\hline rs35163060 & chr19 & 1003158 & 0.002879 & GRIN3B & Best SNP in PGC & failed & - \\
\hline rs187720814 & chr8 & 145064304 & 0.1802 & GRINA & Best SNP in PGC & failed & - \\
\hline rs2206956 & chr6 & 146739228 & 0.0008147 & GRM1 & Best SNP in PGC & pass & 0.3415 \\
\hline rs113426529 & chr3 & 51746239 & 0.03932 & GRM2 & Best SNP in PGC & excluded after QC & 0.01852 \\
\hline rs12704290 & chr7 & 86427626 & $1.04 \mathrm{E}-10$ & GRM3 & Best SNP in PGC & failed & - \\
\hline rs3778049 & chr6 & 34000334 & 0.002248 & GRM4 & Best SNP in PGC & pass & 0.169 \\
\hline rs12364009 & chr11 & 88484625 & 0.0007805 & GRM5 & Best SNP in PGC & failed & - \\
\hline rs79615824 & chr5 & 178411788 & 0.1188 & GRM6 & Best SNP in PGC & excluded after QC & 0.03505 \\
\hline rs1516570 & chr3 & 7005021 & $1.21 \mathrm{E}-05$ & GRM7 & Best SNP in PGC & pass & 0.3403 \\
\hline rs34108879 & chr7 & 126533413 & 0.0006322 & GRM8 & Best SNP in PGC & failed & - \\
\hline rs7806785 & chr7 & 86446316 & 8.69E-05 & GRM3 & Tag SNP representing 10 SNPs & pass & 0.3231 \\
\hline rs10772718 & chr12 & 14042569 & 0.04944 & GRIN2B & Tag SNP representing 11 SNPs & pass & 0.4375 \\
\hline rs2173506 & chr3 & 7109343 & 0.02207 & GRM7 & Tag SNP representing 11 SNPs & pass & 0.4954 \\
\hline rs6943659 & chr7 & 86395926 & 0.02853 & GRM3 & Tag SNP representing 12 SNPs & pass & 0.338 \\
\hline rs13224108 & chr7 & 126595060 & 0.00384 & GRM8 & Tag SNP representing 12 SNPs & pass & 0.1651 \\
\hline rs982339 & chr7 & 86399943 & 0.001183 & GRM3 & Tag SNP representing 13 SNPs & pass & 0.2269 \\
\hline rs9924590 & chr16 & 10198160 & 0.004941 & GRIN2A & Tag SNP representing 17 SNPs & excluded after QC & 0.4179 \\
\hline rs10236114 & chr7 & 126211706 & 0.02832 & GRM8 & Tag SNP representing 17 SNPs & pass & 0.2256 \\
\hline rs10274631 & chr7 & 86376791 & 0.0425 & GRM3 & Tag SNP representing 18 SNPs & excluded after QC & 0.3291 \\
\hline rs950789 & chr7 & 126459894 & 0.04188 & GRM8 & Tag SNP representing 19 SNPs & pass & 0.3167 \\
\hline rs9390385 & chr6 & 146732956 & 0.001393 & GRM1 & Tag SNP representing 20 SNPs & pass & 0.3373 \\
\hline rs17047063 & chr3 & 7343584 & 0.02344 & GRM7 & Tag SNP representing 21 SNPs & pass & 0.4907 \\
\hline rs12489402 & chr3 & 7346663 & 0.01915 & GRM7 & Tag SNP representing 22 SNPs & pass & 0.4352 \\
\hline rs2067052 & chr7 & 126576100 & 0.0146 & GRM8 & Tag SNP representing 27 SNPs & pass & 0.3542 \\
\hline rs3808138 & chr7 & 126615249 & 0.03532 & GRM8 & Tag SNP representing 28 SNPs & pass & 0.346 \\
\hline rs17717959 & chr3 & 7481854 & 0.02896 & GRM7 & Tag SNP representing 33 SNPs & pass & 0.412 \\
\hline rs7196095 & chr16 & 9885832 & 2.94E-06 & GRIN2A & Tag SNP representing 34 SNPs & pass & 0.3495 \\
\hline rs11640274 & chr16 & 9986993 & 0.0005092 & GRIN2A & Tag SNP representing 39 SNPs & pass & 0.2245 \\
\hline rs 8052950 & chr16 & 9910348 & $9.68 \mathrm{E}-06$ & GRIN2A & Tag SNP representing 41 SNPs & pass & 0.3056 \\
\hline rs 7205180 & chr16 & 10195584 & 0.02053 & GRIN2A & Tag SNP representing 5 SNPs & pass & 0.5 \\
\hline rs 2300253 & chr12 & 13861951 & 0.001193 & GRIN2B & Tag SNP representing 5 SNPs & pass & 0.4769 \\
\hline rs12208577 & chr6 & 146730405 & 0.004148 & GRM1 & Tag SNP representing 5 SNPs & pass & 0.2977 \\
\hline rs17126 & chr7 & 86471913 & 0.0007028 & GRM3 & Tag SNP representing 5 SNPs & pass & 0.2986 \\
\hline rs308893 & chr11 & 88270912 & 0.01301 & GRM5 & Tag SNP representing 5 SNPs & pass & 0.375 \\
\hline rs8049651 & chr16 & 9943666 & $1.95 \mathrm{E}-06$ & GRIN2A & Tag SNP representing 50 SNPs & pass & 0.2685 \\
\hline rs1805543 & chr12 & 13784313 & 0.004763 & GRIN2B & Tag SNP representing 7 SNPs & excluded after QC & 0.2598 \\
\hline rs10234440 & chr7 & 86420377 & 4.39E-07 & GRM3 & Tag SNP representing 7 SNPs & pass & 0.1667 \\
\hline rs9469690 & chr6 & 34012911 & 0.01449 & GRM4 & Tag SNP representing 7 SNPs & pass & 0.2847 \\
\hline rs9879127 & chr3 & 7371887 & 0.00616 & GRM7 & Tag SNP representing 7 SNPs & pass & 0.4953 \\
\hline rs17863212 & chr7 & 126739666 & 0.02346 & GRM8 & Tag SNP representing 7 SNPs & pass & 0.1852 \\
\hline rs1375075 & chr16 & 10175729 & 0.03155 & GRIN2A & Tag SNP representing 79 SNPs & pass & 0.1455 \\
\hline rs2499677 & chr6 & 34007054 & 0.04234 & GRM4 & Tag SNP representing 8 SNPs & excluded after QC & 0.3471 \\
\hline rs1396409 & chr3 & 7302907 & 0.02254 & GRM7 & Tag SNP representing 8 SNPs & pass & 0.4019 \\
\hline rs9812897 & chr3 & 7277163 & 0.008734 & GRM7 & Tag SNP representing 8 SNPs & pass & 0.3981 \\
\hline rs12447502 & chr16 & 10149278 & 0.01992 & GRIN2A & Tag SNP representing 9 SNPs & pass & 0.481 \\
\hline rs2315272 & chr16 & 9969102 & 0.0002387 & GRIN2A & Tag SNP representing 9 SNPs & pass & 0.3152 \\
\hline rs7196797 & chr16 & 9864569 & 0.002781 & GRIN2A & Tag SNP representing 9 SNPs & pass & 0.4112 \\
\hline rs 2300256 & chr12 & 13868410 & 0.003367 & GRIN2B & Tag SNP representing 9 SNPs & pass & 0.3843 \\
\hline rs2282958 & chr7 & 86280851 & 0.002104 & GRM3 & Tag SNP representing 9 SNPs & pass & 0.09091 \\
\hline rs 802432 & chr7 & 86284433 & 0.0002564 & GRM3 & Tag SNP representing 9 SNPs & pass & 0.2083 \\
\hline rs973716 & chr11 & 88258182 & 0.004673 & GRM5 & Tag SNP representing 9 SNPs & pass & 0.1366 \\
\hline rs12706761 & chr7 & 126740946 & 0.04958 & GRM8 & Tag SNP representing 9 SNPs & pass & 0.2605 \\
\hline
\end{tabular}


Supplementary Table 2: Quantitative association study with full IQ, verbal IQ and performance Q in the PEPP cohort

\begin{tabular}{|c|c|c|c|c|c|c|c|c|c|c|c|c|c|c|c|c|}
\hline & & \multicolumn{5}{|c|}{ Full IQ } & \multicolumn{5}{|c|}{ Verbal IQ } & \multicolumn{5}{|c|}{ Performance IQ } \\
\hline SNP & Gene & $\begin{array}{c}\text { Sample } \\
\text { size }\end{array}$ & Beta value & Standard error & $\begin{array}{c}\text { Uncorrected } \\
\text { P value }\end{array}$ & \begin{tabular}{|c|} 
Corrected \\
P value \\
\end{tabular} & Sample & Beta & Standard error & \begin{tabular}{|c|} 
Uncorrected \\
P value
\end{tabular} & \begin{tabular}{|c|} 
Corrected \\
P value
\end{tabular} & Sample & Beta & Standard error & \begin{tabular}{|c|} 
Uncorrected \\
P value
\end{tabular} & $\begin{array}{c}\text { Corrected } \\
\text { Pvalue }\end{array}$ \\
\hline rs1396409 & GRM7 & 144 & 7.974 & 2.916 & 0.007062 & 0.303666 & 144 & 2.936 & 1.83 & \begin{tabular}{|l|}
0.1108 \\
\end{tabular} & 1 & 144 & 5.142 & $\begin{array}{l}1.523 \\
\end{array}$ & \begin{tabular}{|l|}
0.0009535 \\
\end{tabular} & 0.0410005 \\
\hline rs10236114 & GRM8 & 146 & -10.46 & 3.6 & 0.004257 & 0.183051 & 146 & -5.321 & 2.231 & 0.01839 & 0.79077 & 146 & -4.61 & 1.928 & 0.0181 & 0.7783 \\
\hline rs17126 & GRM3 & 147 & -4.001 & 2.983 & 0.182 & 1 & 147 & -0.1074 & 1.841 & 0.9536 & 1 & 147 & -3.642 & 1.562 & 0.02111 & 0.90773 \\
\hline rs973716 & GRM5 & 147 & 7.805 & 4.081 & 0.05781 & 1 & 147 & 6.331 & 2.479 & 0.01168 & 0.50224 & 147 & 1.19 & 2.189 & 0.5876 & 1 \\
\hline rs 10234440 & GRM3 & 147 & 2.805 & 3.613 & 0.4387 & 1 & 147 & 3.157 & 2.205 & 0.1543 & 1 & 147 & 0.202 & 1.919 & 0.9163 & 1 \\
\hline rs10772718 & GRIN2B & 147 & 1.906 & 2.99 & 0.5249 & 1 & 147 & 0.8637 & 1.835 & 0.6385 & 1 & 147 & 1.086 & 1.585 & 0.4942 & 1 \\
\hline rs11640274 & GRIN2A & 147 & -0.9883 & 3.314 & 0.7659 & 1 & 147 & -0.5456 & 2.032 & 0.7887 & 1 & 147 & -0.04287 & 1.757 & 0.9806 & 1 \\
\hline rs12208577 & GRM1 & 147 & 2.573 & 3.156 & 0.4163 & 1 & 147 & 0.5813 & 1.939 & 0.7648 & 1 & 147 & 2.922 & 1.659 & 0.08031 & 1 \\
\hline rs12447502 & GRIN2A & 143 & 0.5652 & 2.913 & 0.8464 & 1 & 143 & -0.05426 & 1.77 & 0.9756 & 1 & 143 & 1.21 & 1.546 & 0.4353 & 1 \\
\hline rs12489402 & GRM7 & 147 & 3.059 & 2.886 & 0.2909 & 1 & 147 & 2.455 & 1.765 & 0.1663 & 1 & 147 & 0.6757 & 1.535 & 0.6604 & 1 \\
\hline rs12706761 & GRM8 & 146 & 1.613 & 3.243 & 0.6197 & 1 & 146 & 1.004 & 1.994 & 0.6154 & 1 & 146 & 0.2554 & 1.717 & 0.882 & 1 \\
\hline rs 13224108 & GRM8 & 146 & -1.181 & 3.946 & 0.7651 & 1 & 146 & -0.1919 & 2.413 & 0.9367 & 1 & 146 & -1.338 & 2.102 & 0.5254 & 1 \\
\hline rs1337682 & GRIN3A & 146 & -0.6483 & 3.155 & 0.8375 & 1 & 146 & -1.279 & 1.934 & 0.5096 & 1 & 146 & 1.576 & 1.665 & 0.3453 & 1 \\
\hline rs 1375075 & GRIN2A & 144 & 1.424 & 3.878 & 0.7141 & 1 & 144 & 2.836 & 2.377 & 0.2348 & 1 & 144 & -1.713 & 2.044 & 0.4034 & 1 \\
\hline rs 1516570 & GRM7 & 147 & 1.293 & 3.151 & 0.6821 & 1 & 147 & -0.4072 & 1.933 & 0.8335 & 1 & 147 & 1.937 & 1.663 & 0.2461 & 1 \\
\hline rs 17047063 & GRM7 & 146 & -1.542 & 2.833 & 0.5872 & 1 & 146 & -0.9583 & 1.737 & 0.5821 & 1 & 146 & -0.5833 & 1.503 & 0.6985 & 1 \\
\hline rs17717959 & GRM7 & 147 & -1.61 & 2.552 & 0.5291 & 1 & 147 & -0.9472 & 1.565 & 0.546 & 1 & 147 & $\begin{array}{l}-0.161 \\
\end{array}$ & 1.355 & 0.9055 & 1 \\
\hline rs17863212 & GRM8 & 147 & 4.234 & 3.641 & 0.2468 & 1 & 147 & 2.05 & 2.237 & 0.3609 & 1 & 147 & 1.883 & 1.933 & 0.3315 & 1 \\
\hline rs 2067052 & GRM8 & 147 & -1.417 & 2.941 & 0.6306 & 1 & 147 & -1.628 & 1.8 & 0.3671 & 1 & 147 & 0.9504 & 1.558 & 0.5428 & 1 \\
\hline rs2173506 & GRM7 & 147 & -0.1854 & 2.534 & 0.9418 & 1 & 147 & -0.07975 & 1.554 & 0.9591 & 1 & 147 & -0.08256 & 1.344 & 0.9511 & 1 \\
\hline rs22206956 & GRM1 & 139 & 6.236 & 3.023 & 0.041 & 1 & 139 & 2.476 & 1.866 & 0.1866 & 1 & 139 & 3.335 & 1.606 & 0.03976 & 1 \\
\hline rs22282958 & GRM3 & 143 & -3.619 & 5.419 & 0.5054 & 1 & 143 & 0.03406 & 3.316 & 0.9918 & 1 & 143 & -3.933 & 2.859 & 0.1711 & 1 \\
\hline rs 2300253 & GRIN2B & 147 & -1.207 & 2.571 & 0.6395 & 1 & 147 & -0.9958 & 1.575 & 0.5283 & 1 & 147 & -0.2197 & 1.364 & 0.8722 & 1 \\
\hline rs2300256 & GRIN2B & 147 & 3.799 & 2.932 & 0.1971 & 1 & 147 & 1.263 & 1.805 & 0.4853 & 1 & 147 & 2.684 & 1.547 & 0.08487 & 1 \\
\hline rs 2315272 & GRIN2A & 146 & -3.259 & 2.911 & 0.2647 & 1 & 146 & -1.496 & 1.789 & 0.4044 & 1 & 146 & -1.56 & 1.544 & 0.3142 & 1 \\
\hline rs308893 & GRM5 & 147 & -2.891 & 3.061 & 0.3466 & 1 & 147 & -0.5992 & 1.882 & 0.7507 & 1 & 147 & -1.533 & 1.623 & 0.3463 & 1 \\
\hline rs3778049 & GRM4 & 147 & 6.304 & 3.28 & 0.05654 & 1 & 147 & 2.755 & 2.024 & 0.1755 & 1 & 147 & 3.281 & 1.739 & 0.06122 & 1 \\
\hline rs 3808138 & GRM8 & 143 & 4.165 & 3.389 & 0.2211 & 1 & 143 & 3.12 & 2.088 & 0.1374 & 1 & 143 & 0.5395 & 1.795 & 0.7642 & 1 \\
\hline rs6943659 & GRM3 & 147 & -2.456 & 2.902 & 0.3988 & 1 & 147 & 0.5191 & 1.784 & 0.7714 & 1 & 147 & -2.796 & 1.525 & 0.0687 & 1 \\
\hline rs7196095 & GRIN2A & 147 & -1.176 & 2.908 & 0.6865 & 1 & 147 & -1.541 & 1.779 & 0.3881 & 1 & 147 & 0.5433 & 1.542 & 0.725 & 1 \\
\hline rs7196797 & GRIN2A & 146 & 0.05662 & 2.937 & 0.9846 & 1 & 146 & -0.8771 & 1.779 & 0.6228 & 1 & 146 & 1.627 & 1.56 & 0.2985 & 1 \\
\hline rs7205180 & GRIN2A & 143 & 2.952 & 2.823 & 0.2975 & 1 & 143 & 1.598 & 1.729 & 0.3569 & 1 & 143 & 1.365 & 1.484 & 0.3594 & 1 \\
\hline rs7806785 & GRM3 & 144 & -1.895 & 2.753 & 0.4923 & 1 & 144 & 0.4733 & 1.683 & 0.7789 & 1 & 144 & -2.199 & 1.448 & 0.131 & 1 \\
\hline rs802432 & GRM3 & 147 & 0.8661 & 3.183 & 0.7859 & 1 & 147 & 1.153 & 1.95 & 0.5553 & 1 & 147 & 0.05023 & 1.688 & 0.9763 & 1 \\
\hline rs8049651 & GRIN2A & 147 & 0.1917 & 3.13 & 0.9513 & 1 & 147 & -0.2579 & 1.92 & 0.8933 & 1 & 147 & 0.7622 & 1.658 & 0.6465 & 1 \\
\hline $\mathrm{rs} 8052950$ & GRIN2A & 147 & $\begin{array}{l}-1.323 \\
\end{array}$ & 2.993 & 0.6592 & 1 & 147 & $\begin{array}{l}-1.047 \\
\end{array}$ & 1.835 & 0.5691 & 1 & 147 & -0.01803 & 1.588 & 0.991 & 1 \\
\hline rs9390385 & GRM1 & 141 & 5.047 & 3.072 & 0.1026 & 1 & 141 & 1.961 & 1.924 & 0.3098 & 1 & 141 & 2.653 & 1.615 & 0.1028 & 1 \\
\hline rs94469690 & GRM4 & 147 & 1.965 & 2.809 & 0.4854 & 1 & 147 & 1.376 & 1.722 & 0.4254 & 1 & 147 & 0.2647 & 1.491 & 0.8594 & 1 \\
\hline rs950789 & GRM8 & 142 & 0.4559 & 3.192 & 0.8866 & 1 & 142 & -1.275 & 1.955 & 0.5154 & 1 & 142 & 1.325 & 1.685 & 0.4328 & 1 \\
\hline rs9812897 & GRM7 & 147 & -1.359 & 2.959 & 0.6468 & 1 & 147 & 0.004356 & 1.816 & 0.9981 & 1 & 147 & -1.233 & 1.567 & 0.4325 & 1 \\
\hline rs982339 & GRM3 & 147 & 2.934 & 3.298 & 0.3752 & 1 & 147 & 2.658 & 2.016 & 0.1893 & 1 & 147 & 0.6587 & 1.752 & 0.7075 & 1 \\
\hline rs98879127 & GRM7 & 146 & 1.299 & 2.929 & 0.658 & 1 & 146 & -1.838 & 1.771 & 0.301 & 1 & 146 & 3.165 & 1.54 & 0.0417 & 1 \\
\hline rs9922678 & GRIN2A & 147 & -1.788 & 2.849 & 0.5314 & 1 & 147 & -0.6792 & 1.749 & 0.6983 & 1 & 147 & $\begin{array}{l}-0.9292 \\
\end{array}$ & 1.511 & 0.5394 & 1 \\
\hline
\end{tabular}




\section{Author contribution}

BC, SMS, MOK, JLS and RJ designed the study. GAR, MOK, JLS and RJ obtained funding and supervised the study. BC, SMS, ML, AM, SNI, OK and contributors of the ICAAR study group collected the data. $B C$ analyzed the data. $B C, S M S$, and PAD interpreted the data. BC, SMS, PAD, JLS and RJ drafted the report. All authors and contributors of the ICAAR study group read and approved the final manuscript.

\section{Conflicts of interest}

Dr. Joober reports to be a speaker and/or consulting committee member for Pfizer, Janssen, BMS, Sunovian, Myelin, Otsuka, Lundbeck, shire and Perdue, and to have received grants from Janssen, BMS, Otsuka, Lundbeck, Astra Zeneca and HLS, and to have royalties from Henry Stewart talks, all outside the submitted work.

Dr. Malla served as a research consultant to and gave lectures at conferences supported by Lundbeck and Otsuka and was on an advisory board meeting for the same two companies for which he received honoraria.

Pr. Krebs has received honoraria from and participated in advisory boards or did educational conference for F. Hoffmann-La Roche, Janssen Cilag and Otsuka-Lundbeck. She received financial support for investigator-driven educational initiative from Eisai, Janssen Cilag and OtsukaLundbeck.

Dr. Lepage reports grants from Otsuka Lundbeck Alliance, personal fees from Otsuka Canada, personal fees from Lundbeck Canada, grants and personal fees from Janssen, personal fees from MedAvante-Prophase, personal fees from Amplexor, outside the submitted work.

Dr. Chaumette has received speaking fees from Janssen Cilag, outside the submitted work.

All authors declare they have no conflict of interest related to this article. The contributing Group members (ICAAR study group) declare no conflict of interest.

\section{Role of the sponsors}

The sponsors had no role in the design and conduct of the study, in the collection, management, analysis or interpretation of the data, in the preparation, review or approval of the manuscript, or in the decision to submit the manuscript for publication.

\section{Acknowledgements}

We would like to thank all the patients and parents who participated in the study. We would like to thank Nadia Zeramdini for the handling of the samples in the FEP cohort and the technical supervision of the genotyping. We thank present and past members of the PEPP-Montreal program for technical and clinical assistance, as well as all the practitioners from the C'JAAD team (Centre d'Evaluation pour Jeunes Adultes et Adolescents), at the Service Hospitalo-Universitaire, Centre Hospitalier Sainte-Anne. The PEPP cohort was supported in part by grants from the Fonds 
de la recherche en santé du Québec and the Canadian Institutes of Health Research. The genetic analyses for the PEPP cohort were funded by a grant from the Stairs Foundation. The ICAAR cohort was supported by a grant by the French Government's Agence Nationale pour la Recherche (ANR, 08-MNP-007) and a grant by the French Ministry of Health's Programme Hospitalier de Recherche Clinique (PHRC, AOM-07-118). The Centre Hospitalier Sainte-Anne promoted the study. This work has been supported by the French government's "Investissements d'Avenir" programme, which is managed by the Agence Nationale de la Recherche (ANR), under the reference ANR-18-RHUS0014 (PsyCARE project). Additional financial support was obtained from the Institut National de la Santé et de la Recherche Médicale (INSERM), Université Paris Descartes (recurrent funding). Boris Chaumette has received a postdoctoral fellowship from the Healthy Brains for Healthy Lives project (Talent program) and a grant from the fondation Bettencourt Schueller. Sarojini M. Sengupta is a recipient of the Young Investigator Award from the Brain and Behaviour Foundation (NARSAD) and Dr.Mortimer D. Sackler Developmental Psychology Investigator Award.

\section{References}

Aas, M., Dazzan, P., Mondelli, V., Melle, I., Murray, R.M., Pariante, C.M., 2014. A systematic review of cognitive function in first-episode psychosis, including a discussion on childhood trauma, stress, and inflammation. Front. Psychiatry 4, 182. https://doi.org/10.3389/fpsyt.2013.00182

Agnew-Blais, J., Seidman, L.J., 2013. Neurocognition in youth and young adults under age 30 at familial risk for schizophrenia: a quantitative and qualitative review. Cognit. Neuropsychiatry 18, 44-82. https://doi.org/10.1080/13546805.2012.676309

Anticevic, A., Gancsos, M., Murray, J.D., Repovs, G., Driesen, N.R., Ennis, D.J., Niciu, M.J., Morgan, P.T., Surti, T.S., Bloch, M.H., Ramani, R., Smith, M.A., Wang, X.-J., Krystal, J.H., Corlett, P.R., 2012. NMDA receptor function in large-scale anticorrelated neural systems with implications for cognition and schizophrenia. Proc. Natl. Acad. Sci. U. S. A. 109, 16720-16725. https://doi.org/10.1073/pnas.1208494109

Bassett, A.S., Lowther, C., Merico, D., Costain, G., Chow, E.W.C., van Amelsvoort, T., McDonaldMcGinn, D., Gur, R.E., Swillen, A., Van den Bree, M., Murphy, K., Gothelf, D., Bearden, C.E., Eliez, S., Kates, W., Philip, N., Sashi, V., Campbell, L., Vorstman, J., Cubells, J., Repetto, G.M., Simon, T., Boot, E., Heung, T., Evers, R., Vingerhoets, C., van Duin, E., Zackai, E., Vergaelen, E., Devriendt, K., Vermeesch, J.R., Owen, M., Murphy, C., Michaelovosky, E., Kushan, L., Schneider, M., Fremont, W., Busa, T., Hooper, S., McCabe, K., Duijff, S., Isaev, K., Pellecchia, G., Wei, J., Gazzellone, M.J., Scherer, S.W., Emanuel, B.S., Guo, T., Morrow, B.E., Marshall, C.R., International 22q11.2DS Brain and Behavior Consortium, 2017. Rare Genome-Wide Copy Number Variation and Expression of Schizophrenia in 22q11.2 Deletion Syndrome. Am. J. Psychiatry appiajp201716121417. https://doi.org/10.1176/appi.ajp.2017.16121417

Bodkin, J.A., Coleman, M.J., Godfrey, L.J., Carvalho, C.M.B., Morgan, C.J., Suckow, R.F., Anderson, T., Öngür, D., Kaufman, M.J., Lewandowski, K.E., Siegel, A.J., Waldstreicher, E., Grochowski, C.M., Javitt, D.C., Rujescu, D., Hebbring, S., Weinshilboum, R., Rodriguez, S.B., Kirchhoff, C., Visscher, T., Vuckovic, A., Fialkowski, A., McCarthy, S., Malhotra, D., Sebat, J., Goff, D.C., Hudson, J.I., Lupski, J.R., Coyle, J.T., Rudolph, U., Levy, D.L., 2019. Targeted Treatment of Individuals With Psychosis Carrying a Copy Number Variant 
Containing a Genomic Triplication of the Glycine Decarboxylase Gene. Biol. Psychiatry 86, 523-535. https://doi.org/10.1016/j.biopsych.2019.04.031

Bora, E., Murray, R.M., 2014. Meta-analysis of cognitive deficits in ultra-high risk to psychosis and first-episode psychosis: do the cognitive deficits progress over, or after, the onset of psychosis? Schizophr. Bull. 40, 744-755. https://doi.org/10.1093/schbul/sbt085

Brewer, W.J., Wood, S.J., Phillips, L.J., Francey, S.M., Pantelis, C., Yung, A.R., Cornblatt, B., McGorry, P.D., 2006. Generalized and Specific Cognitive Performance in Clinical HighRisk Cohorts: A Review Highlighting Potential Vulnerability Markers for Psychosis. Schizophr. Bull. 32, 538-555. https://doi.org/10.1093/schbul/sbj077

Buchy, L., Seidman, L.J., Cadenhead, K.S., Cannon, T.D., Cornblatt, B.A., McGlashan, T.H., Perkins, D.O., Stone, W., Tsuang, M.T., Walker, E.F., Woods, S.W., Bearden, C.E., Mathalon, D.H., Addington, J., 2015. Evaluating the relationship between cannabis use and IQ in youth and young adults at clinical high risk of psychosis. Psychiatry Res. 230, 878-884. https://doi.org/10.1016/j.psychres.2015.11.033

Carrión, R.E., Walder, D.J., Auther, A.M., McLaughlin, D., Zyla, H.O., Adelsheim, S., Calkins, R., Carter, C.S., McFarland, B., Melton, R., Niendam, T., Ragland, J.D., Sale, T.G., Taylor, S.F., McFarlane, W.R., Cornblatt, B.A., 2018. From the psychosis prodrome to the firstepisode of psychosis: No evidence of a cognitive decline. J. Psychiatr. Res. 96, 231-238. https://doi.org/10.1016/j.jpsychires.2017.10.014

Chiu, P.W., Lui, S.S.Y., Hung, K.S.Y., Chan, R.C.K., Chan, Q., Sham, P.C., Cheung, E.F.C., Mak, H.K.F., 2017. In vivo gamma-aminobutyric acid and glutamate levels in people with firstepisode schizophrenia: A proton magnetic resonance spectroscopy study. Schizophr. Res. https://doi.org/10.1016/j.schres.2017.07.021

Choi, K.H., Zepp, M.E., Higgs, B.W., Weickert, C.S., Webster, M.J., 2009. Expression profiles of schizophrenia susceptibility genes during human prefrontal cortical development. J. Psychiatry Neurosci. JPN 34, 450-458.

Cohen, C.I., Murante, T., 2017. A prospective analysis of the role of cognition in three models of aging and schizophrenia. Schizophr. Res. https://doi.org/10.1016/j.schres.2017.06.022

Elia, J., Glessner, J.T., Wang, K., Takahashi, N., Shtir, C.J., Hadley, D., Sleiman, P.M.A., Zhang, H., Kim, C.E., Robison, R., Lyon, G.J., Flory, J.H., Bradfield, J.P., Imielinski, M., Hou, C., Frackelton, E.C., Chiavacci, R.M., Sakurai, T., Rabin, C., Middleton, F.A., Thomas, K.A., Garris, M., Mentch, F., Freitag, C.M., Steinhausen, H.-C., Todorov, A.A., Reif, A., Rothenberger, A., Franke, B., Mick, E.O., Roeyers, H., Buitelaar, J., Lesch, K.-P., Banaschewski, T., Ebstein, R.P., Mulas, F., Oades, R.D., Sergeant, J., Sonuga-Barke, E., Renner, T.J., Romanos, M., Romanos, J., Warnke, A., Walitza, S., Meyer, J., Pálmason, H., Seitz, C., Loo, S.K., Smalley, S.L., Biederman, J., Kent, L., Asherson, P., Anney, R.J.L., Gaynor, J.W., Shaw, P., Devoto, M., White, P.S., Grant, S.F.A., Buxbaum, J.D., Rapoport, J.L., Williams, N.M., Nelson, S.F., Faraone, S.V., Hakonarson, H., 2011. Genome-wide copy number variation study associates metabotropic glutamate receptor gene networks with attention deficit hyperactivity disorder. Nat. Genet. 44, 78-84. https://doi.org/10.1038/ng.1013

Fusar-Poli, P., Deste, G., Smieskova, R., Barlati, S., Yung, A.R., Howes, O., Stieglitz, R.-D., Vita, A., McGuire, P., Borgwardt, S., 2012. Cognitive functioning in prodromal psychosis: a metaanalysis. Arch. Gen. Psychiatry 69, 562-571. https://doi.org/10.1001/archgenpsychiatry.2011.1592

Grau, N., Rubio-Abadal, E., Usall, J., Barajas, A., Butjosa, A., Dolz, M., Baños, I., Sánchez, B., Rodríguez, M.J., Peláez, T., Sammut, S., Carlson, J., Huerta-Ramos, E., GENIPE Group, Ochoa, S., 2016. Influence of cognition, premorbid adjustment and psychotic symptoms 
on psycho-social functioning in first-episode psychosis. Psychiatry Res. 242, 157-162. https://doi.org/10.1016/j.psychres.2016.04.121

Green, M.F., Harvey, P.D., 2014. Cognition in schizophrenia: Past, present, and future. Schizophr. Res. Cogn. 1, e1-e9. https://doi.org/10.1016/j.scog.2014.02.001

Hulkko, A.P., Murray, G.K., Moilanen, J., Haapea, M., Rannikko, I., Jones, P.B., Barnett, J.H., Huhtaniska, S., Isohanni, M.K., Koponen, H., Jääskeläinen, E., Miettunen, J., 2017. Lifetime use of psychiatric medications and cognition at 43years of age in schizophrenia in the Northern Finland Birth Cohort 1966. Eur. Psychiatry 45, 50-58. https://doi.org/10.1016/j.eurpsy.2017.06.004

Husa, A.P., Rannikko, I., Moilanen, J., Haapea, M., Murray, G.K., Barnett, J., Jones, P.B., Isohanni, M., Koponen, H., Miettunen, J., Jääskeläinen, E., 2014. Lifetime use of antipsychotic medication and its relation to change of verbal learning and memory in midlife schizophrenia - An observational 9-year follow-up study. Schizophr. Res. 158, 134-141. https://doi.org/10.1016/j.schres.2014.06.035

Iwata, Y., Nakajima, S., Suzuki, T., Keefe, R., Plitman, E., Chung, J., Caravaggio, F., Mimura, M., Graff-Guerrero, A., Uchida, H., 2015. Effects of glutamate positive modulators on cognitive deficits in schizophrenia: a systematic review and meta-analysis of doubleblind randomized controlled trials. Mol. Psychiatry 20, 1151-1160. https://doi.org/10.1038/mp.2015.68

Iyer, S., Jordan, G., MacDonald, K., Joober, R., Malla, A., 2015. Early intervention for psychosis: a Canadian perspective. J. Nerv. Ment. Dis. 203, 356-364. https://doi.org/10.1097/NMD.0000000000000288

Kahn, R.S., Sommer, I.E., Murray, R.M., Meyer-Lindenberg, A., Weinberger, D.R., Cannon, T.D., O’Donovan, M., Correll, C.U., Kane, J.M., van Os, J., Insel, T.R., 2015. Schizophrenia. Nat. Rev. Dis. Primer 15067. https://doi.org/10.1038/nrdp.2015.67

Kandaswamy, R., McQuillin, A., Curtis, D., Gurling, H., 2014. Allelic association, DNA resequencing and copy number variation at the metabotropic glutamate receptor GRM7 gene locus in bipolar disorder. Am. J. Med. Genet. Part B Neuropsychiatr. Genet. Off. Publ. Int. Soc. Psychiatr. Genet. 165B, 365-372. https://doi.org/10.1002/ajmg.b.32239

Kantrowitz, J.T., Malhotra, A.K., Cornblatt, B., Silipo, G., Balla, A., Suckow, R.F., D'Souza, C., Saksa, J., Woods, S.W., Javitt, D.C., 2010. High dose D-serine in the treatment of schizophrenia. Schizophr. Res. 121, 125-130. https://doi.org/10.1016/j.schres.2010.05.012

Kantrowitz, J.T., Woods, S.W., Petkova, E., Cornblatt, B., Corcoran, C.M., Chen, H., Silipo, G., Javitt, D.C., 2015. D-serine for the treatment of negative symptoms in individuals at clinical high risk of schizophrenia: a pilot, double-blind, placebo-controlled, randomised parallel group mechanistic proof-of-concept trial. Lancet Psychiatry 2, 403-412. https://doi.org/10.1016/S2215-0366(15)00098-X

Khandaker, G.M., Barnett, J.H., White, I.R., Jones, P.B., 2011. A quantitative meta-analysis of population-based studies of premorbid intelligence and schizophrenia. Schizophr. Res. 132, 220-227. https://doi.org/10.1016/j.schres.2011.06.017

Kim, S.-Y., Kaufman, M.J., Cohen, B.M., Jensen, J.E., Coyle, J.T., Du, F., Öngür, D., 2017. In Vivo Brain Glycine and Glutamate Concentrations in Patients With First-Episode Psychosis Measured by Echo Time-Averaged Proton Magnetic Resonance Spectroscopy at 4T. Biol. Psychiatry. https://doi.org/10.1016/j.biopsych.2017.08.022

Krebs, M.-O., Magaud, E., Willard, D., Elkhazen, C., Chauchot, F., Gut, A., Morvan, Y., Bourdel, M.-C., Kazes, M., 2014. [Assessment of mental states at risk of psychotic transition: 
validation of the French version of the CAARMS]. L'Encéphale 40, 447-456.

https://doi.org/10.1016/j.encep.2013.12.003

Leiderman, E., Zylberman, I., Zukin, S.R., Cooper, T.B., Javitt, D.C., 1996. Preliminary investigation of high-dose oral glycine on serum levels and negative symptoms in schizophrenia: an open-label trial. Biol. Psychiatry 39, 213-215. https://doi.org/10.1016/00063223(95)00585-4

Lencz, T., Knowles, E., Davies, G., Guha, S., Liewald, D.C., Starr, J.M., Djurovic, S., Melle, I., Sundet, K., Christoforou, A., Reinvang, I., Mukherjee, S., DeRosse, P., Lundervold, A., Steen, V.M., John, M., Espeseth, T., Räikkönen, K., Widen, E., Palotie, A., Eriksson, J.G., Giegling, I., Konte, B., Ikeda, M., Roussos, P., Giakoumaki, S., Burdick, K.E., Payton, A., Ollier, W., Horan, M., Donohoe, G., Morris, D., Corvin, A., Gill, M., Pendleton, N., Iwata, N., Darvasi, A., Bitsios, P., Rujescu, D., Lahti, J., Hellard, S.L., Keller, M.C., Andreassen, O.A., Deary, I.J., Glahn, D.C., Malhotra, A.K., 2014. Molecular genetic evidence for overlap between general cognitive ability and risk for schizophrenia: a report from the Cognitive Genomics consorTium (COGENT). Mol. Psychiatry 19, 168-174. https://doi.org/10.1038/mp.2013.166

Li, W., Ju, K., Li, Z., He, K., Chen, J., Wang, Q., Yang, B., An, L., Feng, G., Sun, W., Zhou, J., Zhang, S., Song, P., Khan, R., Ji, W., Shi, Y., 2016. Significant association of GRM7 and GRM8 genes with schizophrenia and major depressive disorder in the Han Chinese population. Eur. Neuropsychopharmacol. J. Eur. Coll. Neuropsychopharmacol. 26, 136-146. https://doi.org/10.1016/j.euroneuro.2015.05.004

Liang, W., Yu, H., Su, Y., Lu, T., Yan, H., Yue, W., Zhang, D., 2020. Variants of GRM7 as risk factor and response to antipsychotic therapy in schizophrenia. Transl. Psychiatry 10. https://doi.org/10.1038/s41398-020-0763-4

Liu, Y., Zhang, Y., Zhao, D., Dong, R., Yang, X., Tammimies, K., Uddin, M., Scherer, S.W., Gai, Z., 2015. Rare de novo deletion of metabotropic glutamate receptor 7 (GRM7) gene in a patient with autism spectrum disorder. Am. J. Med. Genet. Part B Neuropsychiatr. Genet. Off. Publ. Int. Soc. Psychiatr. Genet. 168B, 258-264. https://doi.org/10.1002/ajmg.b.32306

Magaud, E., Morvan, Y., Rampazzo, A., Alexandre, C., Willard, D., Gaillard, R., Kazes, M., Krebs, M.-O., 2014. Subjects at Ultra High Risk for psychosis have "heterogeneous" intellectual functioning profile: a multiple-case study. Schizophr. Res. 152, 415-420. https://doi.org/10.1016/j.schres.2013.11.002

Mam-Lam-Fook, C., Danset-Alexandre, C., Pedron, L., Amado, I., Gaillard, R., Krebs, M.-O., 2017. Neuropsychology of subjects with ultra-high risk (UHR) of psychosis: A critical analysis of the literature. L'Encephale 43, 241-253. https://doi.org/10.1016/j.encep.2017.02.001

Matosin, N., Newell, K.A., 2013. Metabotropic glutamate receptor 5 in the pathology and treatment of schizophrenia. Neurosci. Biobehav. Rev. 37, 256-268. https://doi.org/10.1016/j.neubiorev.2012.12.005

Merritt, K., Egerton, A., Kempton, M.J., Taylor, M.J., McGuire, P.K., 2016. Nature of Glutamate Alterations in Schizophrenia: A Meta-analysis of Proton Magnetic Resonance Spectroscopy Studies. JAMA Psychiatry 73, 665-674. https://doi.org/10.1001/jamapsychiatry.2016.0442

Millan, M.J., Andrieux, A., Bartzokis, G., Cadenhead, K., Dazzan, P., Fusar-Poli, P., Gallinat, J., Giedd, J., Grayson, D.R., Heinrichs, M., Kahn, R., Krebs, M.-O., Leboyer, M., Lewis, D., Marin, O., Marin, P., Meyer-Lindenberg, A., McGorry, P., McGuire, P., Owen, M.J., Patterson, P., Sawa, A., Spedding, M., Uhlhaas, P., Vaccarino, F., Wahlestedt, C., 
Weinberger, D., 2016. Altering the course of schizophrenia: progress and perspectives. Nat. Rev. Drug Discov. https://doi.org/10.1038/nrd.2016.28

Nuechterlein, K.H., Ventura, J., Subotnik, K.L., Bartzokis, G., 2014. The early longitudinal course of cognitive deficits in schizophrenia. J. Clin. Psychiatry 75 Suppl 2, 25-29. https://doi.org/10.4088/JCP.13065.su1.06

Oppetit, A., Bourgin, J., Martinez, G., Kazes, M., Mam-Lam-Fook, C., Gaillard, R., Olié, J.-P., Krebs, M.-O., 2016. The C'JAAD: a French team for early intervention in psychosis in Paris. Early Interv. Psychiatry. https://doi.org/10.1111/eip.12376

Owen, M.J., Sawa, A., Mortensen, P.B., 2016. Schizophrenia. Lancet Lond. Engl. 388, 86-97. https://doi.org/10.1016/S0140-6736(15)01121-6

Plitman, E., de la Fuente-Sandoval, C., Reyes-Madrigal, F., Chavez, S., Gómez-Cruz, G., LeónOrtiz, P., Graff-Guerrero, A., 2016. Elevated Myo-Inositol, Choline, and Glutamate Levels in the Associative Striatum of Antipsychotic-Naive Patients With First-Episode Psychosis: A Proton Magnetic Resonance Spectroscopy Study With Implications for Glial Dysfunction. Schizophr. Bull. 42, 415-424. https://doi.org/10.1093/schbul/sbv118

Plomin, R., Stumm, S. von, 2018. The new genetics of intelligence. Nat. Rev. Genet. 19, 148-159. https://doi.org/10.1038/nrg.2017.104

Reuter, M.S., Tawamie, H., Buchert, R., Hosny Gebril, O., Froukh, T., Thiel, C., Uebe, S., Ekici, A.B., Krumbiegel, M., Zweier, C., Hoyer, J., Eberlein, K., Bauer, J., Scheller, U., Strom, T.M., Hoffjan, S., Abdelraouf, E.R., Meguid, N.A., Abboud, A., Al Khateeb, M.A., Fakher, M., Hamdan, S., Ismael, A., Muhammad, S., Abdallah, E., Sticht, H., Wieczorek, D., Reis, A., Abou Jamra, R., 2017. Diagnostic Yield and Novel Candidate Genes by Exome Sequencing in 152 Consanguineous Families With Neurodevelopmental Disorders. JAMA Psychiatry 74, 293-299. https://doi.org/10.1001/jamapsychiatry.2016.3798

Sacchetti, E., Magri, C., Minelli, A., Valsecchi, P., Traversa, M., Calza, S., Vita, A., Gennarelli, M., 2017. The GRM7 gene, early response to risperidone, and schizophrenia: a genomewide association study and a confirmatory pharmacogenetic analysis. Pharmacogenomics J. 17, 146-154. https://doi.org/10.1038/tpj.2015.90

Skene, N.G., Bryois, J., Bakken, T.E., Breen, G., Crowley, J.J., Gaspar, H.A., Giusti-Rodriguez, P., Hodge, R.D., Miller, J.A., Muñoz-Manchado, A.B., O’Donovan, M.C., Owen, M.J., Pardiñas, A.F., Ryge, J., Walters, J.T.R., Linnarsson, S., Lein, E.S., Sullivan, P.F., HjerlingLeffler, J., 2018. Genetic identification of brain cell types underlying schizophrenia. Nat. Genet. 50, 825-833. https://doi.org/10.1038/s41588-018-0129-5

Smeland, O.B., Frei, O., Kauppi, K., Hill, W.D., Li, W., Wang, Y., Krull, F., Bettella, F., Eriksen, J.A., Witoelar, A., Davies, G., Fan, C.C., Thompson, W.K., Lam, M., Lencz, T., Chen, C.-H., Ueland, T., Jönsson, E.G., Djurovic, S., Deary, I.J., Dale, A.M., Andreassen, O.A., NeuroCHARGE (Cohorts for Heart and Aging Research in Genomic Epidemiology) Cognitive Working Group, 2017. Identification of Genetic Loci Jointly Influencing Schizophrenia Risk and the Cognitive Traits of Verbal-Numerical Reasoning, Reaction Time, and General Cognitive Function. JAMA Psychiatry. https://doi.org/10.1001/jamapsychiatry.2017.1986

Sniekers, S., Stringer, S., Watanabe, K., Jansen, P.R., Coleman, J.R.I., Krapohl, E., Taskesen, E., Hammerschlag, A.R., Okbay, A., Zabaneh, D., Amin, N., Breen, G., Cesarini, D., Chabris, C.F., lacono, W.G., Ikram, M.A., Johannesson, M., Koellinger, P., Lee, J.J., Magnusson, P.K.E., McGue, M., Miller, M.B., Ollier, W.E.R., Payton, A., Pendleton, N., Plomin, R., Rietveld, C.A., Tiemeier, H., van Duijn, C.M., Posthuma, D., 2017. Genome-wide association meta-analysis of 78,308 individuals identifies new loci and genes influencing human intelligence. Nat. Genet. 49, 1107-1112. https://doi.org/10.1038/ng.3869 
Spangaro, M., Bosia, M., Bechi, M., Buonocore, M., Cocchi, F., Guglielmino, C., Bianchi, L., Mastromatteo, A., Lorenzi, C., Cavallaro, R., 2018. Neurobiology of cognitive remediation in schizophrenia: Effects of EAAT2 polymorphism. Schizophr. Res. 202, 106110. https://doi.org/10.1016/j.schres.2018.06.059

Spangaro, M., Bosia, M., Zanoletti, A., Bechi, M., Mariachiara, B., Pirovano, A., Lorenzi, C., Bramanti, P., Smeraldi, E., Cavallaro, R., 2014. Exploring effects of EAAT polymorphisms on cognitive functions in schizophrenia. Pharmacogenomics 15, 925-932. https://doi.org/10.2217/pgs.14.42

Stevenson, J.M., Reilly, J.L., Harris, M.S.H., Patel, S.R., Weiden, P.J., Prasad, K.M., Badner, J.A., Nimgaonkar, V.L., Keshavan, M.S., Sweeney, J.A., Bishop, J.R., 2016. Antipsychotic pharmacogenomics in first episode psychosis: a role for glutamate genes. Transl. Psychiatry 6, e739. https://doi.org/10.1038/tp.2016.10

Tarabeux, J., Kebir, O., Gauthier, J., Hamdan, F.F., Xiong, L., Piton, A., Spiegelman, D., Henrion, É., Millet, B., Fathalli, F., Joober, R., Rapoport, J.L., DeLisi, L.E., Fombonne, É., Mottron, L., Forget-Dubois, N., Boivin, M., Michaud, J.L., Drapeau, P., Lafrenière, R.G., Rouleau, G.A., Krebs, M.-O., 2011. Rare mutations in N-methyl-D-aspartate glutamate receptors in autism spectrum disorders and schizophrenia. Transl. Psychiatry 1, e55. https://doi.org/10.1038/tp.2011.52

Thomas, E.H.X., Bozaoglu, K., Rossell, S.L., Gurvich, C., 2017. The influence of the glutamatergic system on cognition in schizophrenia: A systematic review. Neurosci. Biobehav. Rev. 77, 369-387. https://doi.org/10.1016/j.neubiorev.2017.04.005

Toulopoulou, T., Picchioni, M., Rijsdijk, F., Hua-Hall, M., Ettinger, U., Sham, P., Murray, R., 2007. Substantial genetic overlap between neurocognition and schizophrenia: genetic modeling in twin samples. Arch. Gen. Psychiatry 64, 1348-1355. https://doi.org/10.1001/archpsyc.64.12.1348

Vinckier, F., Gaillard, R., Palminteri, S., Rigoux, L., Salvador, A., Fornito, A., Adapa, R., Krebs, M.O., Pessiglione, M., Fletcher, P.C., 2016. Confidence and psychosis: a neurocomputational account of contingency learning disruption by NMDA blockade. Mol. Psychiatry 21, 946-955. https://doi.org/10.1038/mp.2015.73

Wellcome Trust Case Control Consortium, 2007. Genome-wide association study of 14,000 cases of seven common diseases and 3,000 shared controls. Nature 447, 661-678. https://doi.org/10.1038/nature05911

Xia, W., Liu, Y., Jiao, J., 2015. GRM7 Regulates Embryonic Neurogenesis via CREB and YAP. Stem Cell Rep. 4, 795-810. https://doi.org/10.1016/j.stemcr.2015.03.004

Zai, G., Robbins, T.W., Sahakian, B.J., Kennedy, J.L., 2017. A review of molecular genetic studies of neurocognitive deficits in schizophrenia. Neurosci. Biobehav. Rev. 72, 50-67. https://doi.org/10.1016/j.neubiorev.2016.10.024

Zhang, W., Gamazon, E.R., Zhang, X., Konkashbaev, A., Liu, C., Szilágyi, K.L., Dolan, M.E., Cox, N.J., 2015. SCAN database: facilitating integrative analyses of cytosine modification and expression QTL. Database J. Biol. Databases Curation 2015. https://doi.org/10.1093/database/bav025 